\title{
SISTEMA DE PRODUÇÃO, VALOR NUTRICIONAL E EFICIÊNCIA DA PALMA FORRA̧GEIRA NO SEMIÁRIDO: UMA REVISÃO
}

\author{
SILVA, Anderson Samuel ${ }^{1}$ \\ SANTOS, Edson Mauro ${ }^{2}$ \\ RAMOS, João Paulo de Farias ${ }^{2}$ \\ SANTOS, Betina Raquel Cunha Dos ${ }^{2}$ \\ NASCIMENTO, Jhonatan Feitosa do ${ }^{3}$ \\ SÁ, Raniere Paulino de ${ }^{3}$
}

\section{Recebido em: 2019.08.15 Aprovado em: $2020.11 .24 \quad$ ISSUE DOI: $10.3738 / 21751463.3683$}

\begin{abstract}
RESUMO: A adoção de estratégias para criação e produção animal em regiões com escassez de chuvas num determinado período do ano, leva a palma forrageira a ter uma importância significativa nesse cenário. A palma forrageira desempenha papel central no cenário socioeconômico na região Semiárida Brasileira (SB), pois, além de ser uma cultura adaptada as condições edafoclimáticas, gera renda e sustentabilidade financeira. O SB apresenta temperaturas médias elevadas e precipitações médias anuais de 300-700 mm. Diante disso, a produção de palma forrageira é uma das estratégias de apoio à convivência da pecuária regional com a seca. A escolha da colheita de palma forrageira segue em função da necessidade em grande parte dos produtores ou a cada dois anos. Porém, intervalos maiores podem diminuir a eficiência do solo em produzir menos em maiores períodos de tempo, o que sugere frequências de cortes menores para um bom aproveitamento da área utilizada para o cultivo. Dessa forma, será possível manter a produção e aumentar a produtividade ao longo tempo. Diante desse contexto, essa revisão apresenta informações pertinentes para elaboração de um manejo adequado da cultura da palma, levando em consideração os sistemas de produção em sequeiro no semiárido, e sua influência nutricional para fornecimento na dieta animal de ruminantes e não ruminantes.
\end{abstract}

Palavras-chave: Nopalea spp. Palmepa-PB01. Produtividade. Sequeiro.

\section{PRODUCTION SYSTEM, NUTRITIONAL VALUE AND EFFICIENCY OF FORAGE CACTUS IN THE SEMIARID}

SUMMARY: The adoption of strategies for animal husbandry and production in areas with a lack of rainfall in a certain period of the year, makes forage cactus to have a significant importance in this scenario. Forage cactus plays a central role in the socioeconomic scenario in the Brazilian Semi-arid region (SB), due to being a culture adapted to edaphoclimatic conditions, generates income and financial sustainability. SB has high average temperatures and annual average rainfall of 300-700 mm. Given this, the production of forage cactus is one of the strategies to support the coexistence of regional livestock with drought. The choice of forage cactus harvest follows the need of most producers or every two years. However, longer intervals may decrease the efficiency of the soil to produce less in longer periods of time, which suggests lower cutting frequencies for a better use of the area used for cultivation. This will allow you to maintain production and increase productivity over time. Given this context, this review aims to present pertinent information for the elaboration of a good management of cactus crop, taking into account the frequency of harvesting of the plant in a rainfed rainforest system, and its nutritional influence to supply the animal diet of cactus. ruminants and non-ruminants.

Keywords: Nopalea spp., Palmepa-PB01. Productivity. Rainfed.

\footnotetext{
${ }^{1}$ Discente de doutorado em zootecnia pela Universidade Federal da Paraíba, CCA, UFPB-Areia, PB.

${ }^{2}$ Professor(a) do departamento de zootecnia da Universidade Federal da Paraíba, CCA, UFPB-Areia, PB

${ }^{3}$ Mestre em zootecnia pela Universidade Federal da Paraíba, CCA, UFPB-Areia, PB
} 


\section{INTRODUÇÃO}

Os critérios vantajosos observados pela palma forrageira em regiões semiáridas têm contribuído para uma fonte alimentar importante aos animais, sendo fornecida in natura, como silagem na forma de ração completa ou até mesmo em forma de farelo. Rocha et al. (2012) afirmam que o cultivo tem contribuído para a manutenção da biodiversidade da Caatinga (devido a mais essa alternativa de oferta alimentar), aumento significativo da lucratividade pecuária das famílias, entre outros aspectos. Dessa maneira, apresenta grande importância econômica e social no semiárido brasileiro.

Essa forrageira tem seu desenvolvimento vegetal mesmo em condições adversas de precipitação, temperatura, umidade do ar, o que confere uma planta com características para tal evento. Larcher (2000) afirma que diferentemente de outras plantas xerófilas, as cactáceas apresentam seu sistema radicular superficial, que em condições normais, tem uma profundidade máxima de $30 \mathrm{~cm}$., onde o sistema radicular explora totalmente a área superficial do solo, aumentando sua capacidade de absorção de água.

A irregularidade de chuvas se estende por longos períodos, ocasionando sazonalidade de produção forrageiras. Dessa forma, a produção em plena época de estiagem pode suprir a necessidade de alimentos para os animais nessa época, diminuindo perdas econômicas na produção. Devido à grande rusticidade encontrada no semiárido para a produção de forragem, a palma tornou-se um relevante recurso para a alimentação animal, com alta capacidade de oferta de forragem, se comparada a maioria da vegetação disponível nessa região (OLIVEIRA et al., 2010).

A palma auxilia e melhora o valor nutritivo de dietas de baixa qualidade, isso é possível devido a seu alto valor de carboidratos não fibrosos, aumentando ganhos significativos em ruminantes nas pastagens de baixa qualidade, desde que em pequena quantidade e uma fonte de proteína incluída na dieta (DUBEUX JÚNIOR et al. 2017).

A escolha da colheita de palma forrageira segue em função da necessidade em grande parte dos produtores ou a cada dois anos. Porém, intervalos maiores podem diminuir a eficiência do solo em produzir menos em maiores períodos de tempo, o que sugere frequências de cortes menores para um bom aproveitamento da área utilizada para o cultivo. Dessa forma, será possível manter a produção e aumentar a produtividade ao longo tempo (FARIAS et al., 2005).

Diante desse contexto, objetivou-se com essa revisão apresentar informações pertinentes para elaboração de um sistema adequado de cultivo da palma forrageira e sua influência nutricional na dieta de ruminantes e não ruminante. 


\section{A PALMA FORRAGEIRA}

A palma forrageira tem seu cultivo em todo o mundo, e têm diversos fins, dentre eles, destaca-se a principal utilidade que é a produção de forragem (BAYAR et al., 2018; VOLPE et al., 2018). Dessa forma, a palma forrageira desempenha papel importante nas regiões semiáridas do Brasil, devido a diversificações de utilidades, suprindo a necessidade dos animais em períodos de estiagem prolongada. A mesma, tem alta produtividade de matéria fresca por hectare, o que contribui para seu cultivo por pequenos agricultores e pecuaristas de regiões com menores precipitações anuais em sistema de sequeiro. Pode oferecer uma gama de usos bastante extensa e rica, incluindo frutos, polpa, sucos, vitaminas, além de diversificadas combinações com outros alimentos (CÂNDIDO FILHO et al., 2014).

Devido a sua adaptação a condições edafoclimáticas da região semiárida, a palma forrageira se destaca no cenário produtivo devido a seu metabolismo fotossintético CAM (Metabolismo Ácido das Crassuláceas), ocorrendo a abertura dos estômatos para fixação de $\mathrm{CO}_{2}$ apenas a noite, perdendo menos água para o meio através da transpiração (TAIZ et al., 2017).

Quando comparada a plantas de metabolismo C3 e C4 a palma forrageira é mais eficiente no uso da água (kg de MS/ kg de água). Sampaio (2005) afirma que plantas CAM quando comparado as plantas de metabolismo C3, pode chegar até 11 vezes mais em relação a eficiência de uso da água. Nesse cenário, a produção de palma forrageira é uma das estratégias de apoio à convivência da pecuária regional com a seca (SILVA et al., 2012).

Quanto a produção de palma forrageira, a Paraíba se destaca no cenário produtivo, sendo o segundo maior estado produtor do Brasil seguida por Pernambuco, Sergipe e Alagoas, com uma produção de 742.981.605 toneladas, correspondendo a 20,7\% do total do país, perdendo apenas para o estado da Bahia, e constituindo o terceiro maior estado com estabelecimentos produtores dessa forragem com 13.750 propriedades, correspondendo a 10,8\% do país (IBGE, 2017). Diante desse contexto, a palma forrageira apresenta-se bastante difundida na região semiárida do país, o que lhe confere uma grande importância para pequenos e grandes produtores.

Dubeux Júnior et al. (2017), afirmam que no momento de estabelecimento do palmal, deve-se levar em consideração aspectos importantes para um bom desenvolvimento dessa forragem, incluindo a densidade, cultivares, época do ano, controle de praga e doenças, plantas invasoras, entre outros. Isso, consequentemente irá ditar a produtividade futura, além de corrigir alguns problemas preventivamente ao longo da produção.

A adoção de estratégias para criação e produção animal em regiões com escassez de chuvas num determinado período do ano, leva a palma forrageira a ter uma importância 
significativa nesse cenário. Apresenta um papel de suplementar a dieta em épocas de estiagem prolongada, que tem uma redução elevada de qualidade e acúmulo de forragem na seca (LIRA et al., 2017).

\section{CONSIDERAÇÕES BOTÂNICAS E A VARIEDADE PALMEPA-PBO1}

A palma forrageira pertence à Divisão: Embryophyta, Sub-divisão: Angiospermea, Classe: Dicotyledoneae, Sub-classe: Archiclamideae, Ordem: Opuntiales e família Cactácea. Está catalogada mais de 178 gêneros com aproximadamente 2.000 espécies. Porém, apenas os gêneros Opuntia sp. e Nopalea sp. encontram-se as espécies de palma utilizados como forragem (SCHEINVAr, 2012).

Devido a seu metabolismo fotossintético CAM, justificado pela abertura de suas células estomáticas para fixação de $\mathrm{CO}_{2}$ no período noturno, ocorrendo uma redução hídrica para o meio, com pouca transpiração hídrica. A fixação absorvida de $\mathrm{CO}_{2}$ é armazenada temporariamente na forma de malato na célula do vacúolo, onde o mesmo é usado na fotossíntese. Além dessa adaptação fotossintética, a palma apresenta alguns atributos morfológicos que confere sua eficiência para regiões semiáridas, como estruturas de tricomas e células estomáticas profundas com a presença de cutículas nas células epidérmicas (SANTOS et al., 2010).

$\mathrm{O}$ crescimento lento dos artículos da palma forrageira é devido à pouca e dificuldade de incidência fotossintética, causado pela posição dos cladódios em relação ao solo, proporcionando pouca área dos cladódios para realizações fotossintéticas (FARIAS et al., 2005). Dessa maneira, a palma tem um índice de área do cladódio (IAC) muito baixo se comparado a outras plantas forrageiras. O que pode influenciar a dinâmica da frequência de colheita. Lira et al., (2006) afirmam que pelo fato do menor IAC, a prática de manejo pode minimizar esse efeito indesejado através do adensamento de cultivo da palma forrageira ou por intervalos maiores de corte, juntamente com a conservação de cladódios para a mantença do estande.

A atuação de agentes causadores de doenças e pragas é um dos principais entraves da produção de palma. Fatores fitossanitários da palma forrageira podem ser considerados um aspecto limitante para a produção plena dessa cultura (FERRAZ et al., 2017). Dessa maneira, fatores bióticos e abióticos podem afetar a produção do palmal com maior ou menor frequência e intensidade segundo Inglese et al. (2017).

Uma das causas negativas na produção da palma forrageira é sem dúvida a ocorrência da praga conhecida como cochonilha do carmim (Dactylopius opuntiae). O ataque dessa praga pode ocasionar a morte da planta e dizimação do palmal (CAVALCANTI et al., 2001). Ferraz et al. (2016), relatam que o ataque severo da cochonilha do carmim dizimou a produção de forragem na 
cidade de Sertânia, Pernambuco, com um nível de infestação total da área. Com o aumento significativo do cultivo da palma forrageira em regiões semiáridas o controle dessa praga é um fator relevante para o sucesso da produção.

Uma das estratégias de combate a cochonilha é o uso de genótipos resistentes a seu ataque, onde irá diminui custos com pesticidas para o controle. Devido a isso, a escolha da variedade adequada pode ser uma ferramenta eficaz no combate. Pensando nisso, a Empresa Estadual de Pesquisa Agropecuária da Paraíba (Emepa) selecionou a variedade, do gênero Nopalea sp. que apresenta resistência ao inseto-praga: Palmepa-PB1. Essa, também chamada de Mão de Onça, Sertânia, Baiana, já se encontra bem difundida.

De acordo com Silva (2017) a variedade Palmepa-PB1 possui crescimento vertical, boa produtividade, é palatável aos animais, rica em carboidratos não fibrosos, pouca resistência à seca quando comparada à palma gigante e resistente à cochonilha do carmim. Porém, o genótipo é susceptível a cochonilha de escama, o que pode ser um ponto negativo em locais de ocorrência severa dessa praga.

\section{UTILIZAÇÃO DA PALMA FORRAGEIRA NO SEMIÁRIDO E VALOR NUTRICIONAL}

A palma forrageira desempenha papel central no cenário socioeconômico na região Semiárida Brasileira (SAB), devido, além de ser uma cultura adaptada às condições edafoclimáticas, gera renda e sustentabilidade financeira. O SAB apresenta temperaturas médias elevadas e precipitações médias anuais de 300-700 mm. Diante disso, a produção de palma forrageira é uma das estratégias de apoio à convivência da pecuária regional com a seca (SILVA et al., 2012).

Devido à alta umidade encontrado nos artículos da palma forrageira, aproximadamente 90\%, supri parcialmente ou total a necessidade hídrica dos rebanhos, fornecendo não só o volumoso fresco mais também água. O consumo de água por ovinos foi nulo quando o nível de palma forrageira da dieta ultrapassou 300g de MS por dia (BEN SALEM et al., 2002).

Cordova Torres et al. (2017), concluíram que além dessa forrageira ser um volumoso com grande utilidade na suplementação alimentar dos ruminantes pode ser uma fonte única de água na alimentação desses animais no período seco no Semiárido nordestino.

Estudos comprovam que o cultivo da palma forrageira em sistema de sequeiro tem alcançados elevadas produtividades de fitomassa na região semiárida, com altos valores nutricionais e menor consumo de água pelos animais, se comparada as forrageiras nativas dessa 
região, sendo seu desenvolvimento menos influenciado pela variabilidade pluviométrica (MENEZES et al., 2005).

A palma forrageira tem grande vantagem na substituição de alguns alimentos principalmente os energéticos na dieta, diminuindo custos ao produtor com essa fonte, podendo aumentar a competitividade no mercado financeiro com a venda de carne e leite. Em contrapartida a palma tem valores baixos de algumas nutrientes essências para a alimentação, o que o produtor deve ficar atento, pois pode acarretar sérios problemas utilizando apenas a palma como a única fonte de volumoso (NEVES et al., 2010).

Apresentando baixos teores de matéria seca (MS), proteína bruta (PB), fibra em detergente neutro (FDN) e fibra em detergente ácido (FDA), a palma deve ser fornecida junto com outros alimentos para suprir a necessidade nutricional dos animais, sendo valores abaixo para os níveis recomendados para ruminantes. Em geral, os valores de MS variam de 92,5 a 116,9 g.kg-1 ${ }^{1}$, matéria mineral (MM) apresentam valores em torno de 96,7 a 126,2 g· $\mathrm{kg}^{-1}$, extrato etéreo (EE) varia de 17,2 a 22,0 g. $\mathrm{kg}^{-1}$, carboidratos totais (CHT) 772,9 a 837,8 g. $\mathrm{kg}^{-1}$, PB varia de 40,1 a 103,9 g.kg-1 ${ }^{1}$ FDN de 196,5 a 373,2 g.kg-1, FDA de 110,9 a 201,6 g.kg- e carboidratos não fibrosos (CNF) de 423,6 a 557,0 g·kg-1 (MOURA et al., 2012).

Quanto ao gênero Nopalea, tem uma maior exigência aos tratos culturais e demais condições ambientais, porém, apresenta maior teor de matéria seca, carboidratos solúveis e digestibilidade, quando comparada as plantas do gênero Opuntia (SANTOS et al., 2006a). Avaliando a composição bromatológica, Silva et al., (2015) encontram teores de matéria seca de $9 \%$ e 10,33\% para os gêneros Opuntia sp. e Nopalea sp. respectivamente, sendo conduzidas com as mesmas condições de campo.

Silva et al., (2015) afirmam que a palma é colhida a cada dois anos de forma tradicional, pela maioria dos produtores pecuaristas, sendo uma planta semiperene de ciclo bienal em sistema de sequeiro, podendo sofrer modificações no crescimento e desenvolvimento ao longo do ciclo, devido as condições edafoclimáticas. Portanto, o valor nutritivo é influenciado pelo gênero, idade da planta, variedade, manejo de adubação, frequência de corte, capinas, sequeiro ou irrigado, época do ano, densidade de plantio, entre outros (DUBEUX JÚNIOR; SANTOS, 2010).

\section{USO NA ALIMENTAÇÃO ANIMAL}

Nas regiões semiáridas a produção animal sofre com a escassez de alimentos devido sobretudo pela baixa qualidade e quantidade de alimentos disponível principalmente em época de seca do ano. Dessa forma, os animais na sua grande maioria são criados em regime extensivo, sendo supridos pela vegetação nativa, ocasionando baixos índices zootécnicos e deixando de 
expressar seu potencial genético, em virtude da má alimentação. Diante disso, a palma forrageira desempenha um papel importante na suplementação alimentar (LIRA et al., 2017).

Santos et al., (2013) ressaltam que independente da época do ano a palma forrageira contribui para o desempenho e produção de bovinos, caprinos e ovinos na bacia leiteira do Nordeste. Além de proporcionar ganhos econômicos com inserção dessa forragem na dieta pode anular o consumo de água pelos animais. Além de contribuir para o consumo de MS, corroborando com experimento realizado Bispo et al., (2007), que avaliaram a substituição parcial de feno de capim elefante, os autores relataram houve um aumento de consumo de maneira linear de (CMS), o que foi obtido devido a digestibilidade alta da MS e MO e palatabilidade da palma.

Lima et al. (2002), em estudo com vacas mestiças incluindo $50 \%$ de palma, concluiram que além da produção leiteira (15 kg de leite/dia) a inclusão da palma na dieta proporcionou consumo de água menor, o que é favorável para regiões de escassez hídrica. Corroborando com estudo realizado por Cordova Torres et al. (2017), que avaliando o desempenho dos animais com a inserção da palma de 30 e 50\% obtiveram ganhos diários de 174 e 155 g respectivamente, comparado ao tratamento controle, e chegaram a conclusão que a restrição de água não interferiu no ganho de peso e que a palma pode ser ofertada exclusivamente como fonte de água.

Marques et al. (2017), ressaltam que a palma pode ser fornecida aos bovinos, desde que de maneira adequada e em forma de ração balanceada, evitando assim desordens metabólicas. E pode ser incluída de diversas maneiras na dieta animal, em forma de farelo, picada ou servida no cocho. Levando em consideração o baixo nível de MS, e corrigindo o teor de fibra e CNF e correções dos níveis de PB para a ração completa com inclusão da palma na dieta. Para Santos et al. (2006b), a palma possui alta digestibilidade, até superior a silagem do milho e valor energético, no entanto, não devendo ser fornecido sozinha, e conclui que não deve exceder uma inclusão de 40 a $50 \%$ da MS em dietas para bovinos.

Para vacas em lactação Andrade et al. (2002), recomendam para a formulação de ração completa um percentual mínima de $40 \%$ de CNF e 25 de FDN (com 17\% proveniente do volumoso), com intuito de melhorar a digestibilidade e consumo de MS, dessa forma, confirmase a importância de determinar a composição química da palma forrageira para formular a ração aos animais. .

Ferreira et al., (2009) avaliando o desempenho de novilhas da raça Holandês, observaram que a inclusão de palma de 64 a 70\% resultou em ganho médio de peso na ordem de 0,43 a 1,20 $\mathrm{kg} / \mathrm{dia}$, caracterizando um desempenho satisfatório com o uso desse volumoso. Ainda os autores concluíram que a palma pode ser uma alternativa eficiente para alimentação de bovinos, 
ocasionando menor dependência com insumos pecuários, e a utilização da palma tem despertado interesse dos produtores devido a inclusão ser adaptada a diferentes categorias de bovinos.

Para uso na alimentação de monogástricos, Silva et al., (2016) avaliando a inclusão de farelo de palma forrageira na dieta de suínos, concluíram que a inclusão de 5\% pode ser utilizado em condições de não suplementação, porém, é preciso atenção para o uso da palma em dietas de monogástrico por possuírem baixos níveis proteicos e a concentração de fibra encontrado na planta.

\section{FREQUÊNCIA DE COLHEITA}

O uso do pastejo direto na palma forrageira não é ideal, devido ao pisoteio e quebra dos cladódios pelos animais. Dessa maneira, a colheita é o modo mais viável para o produtor. Diante desse contexto, deve-se levar em consideração a frequência dessa colheita, pois colheitas tardias ou precoce da palma pode acarretar perdas significativas e levar os custos de mão de obra, já que não se utilizam colheitas mecânica, os custos do corte são mais elevados (FARIAS et al., 2000).

As condições ideais de fertilidade do solo, precipitação favorável, tratos culturais, e maiores densidades de cultivo favorece colheitas com menores frequências. Porém, essas condições ideais não são encontradas em regiões semiáridas, o que sugere adequar o manejo a diferentes condições. Dessa forma, algumas medidas morfológicas da planta podem dar subsídio para a tomada de decisão correta no momento da colheita, dentre eles o índice de área do cladódio (IAC, $\mathrm{m}^{2} \cdot \mathrm{m}^{-2}$ ), que é a área do cladódio ocupada num metro quadrado de solo, levando em consideração os dois lados dos artículos (SOUZA, 2015).

O mesmo autor afirma que o IAC quando são realizadas colheitas bienais é maior que colheitas anuais (4,4 e 2,2 $\mathrm{m}^{2} \cdot \mathrm{m}^{2}$, respectivamente). Isso é possível provavelmente devido ao estresse, reserva e energia que a palma precisa ter para posteriores brotações na colheita anual, o que leva mais tempo até a planta se estabelecer novamente, e pouca área fotossintética com os cladódios remanescente, diferentemente da bienal que continua crescendo e acumulando reservas, dessa maneira aumentando sua longevidade. Nobel et al. (1995), recomendam, para um aumento da produtividade da palma, um IAC de 4 e $5 \mathrm{~m}^{2} \mathrm{~m}^{2}$.

Ramos (2012) trabalhando com a cultivar Gigante (Opuntia ficus-indica (L.) P. Mill) na Mesorregião do Agreste paraibano na cidade de Soledade-PB e avaliando o crescimento vegetativo e produtividade da palma em função da adubação orgânica e manejo de colheita de palma, verificou que o uso de 10 t/ha de esterco caprino proporcionou ganhos significativos através da colheita anual no primeiro ciclo vegetativo da palma, e afirma que o corte anual pode ser utilizado como prática de manejo da palma forrageira. Porém, ainda não há estudos na 
literatura que comparem e comprovem a eficiência da frequência de colheitas para a var. Palmepa PB01 (Nopalea cochinilifera Salm Dyck).

De maneira geral, a palma forrageira quando manejada corretamente pode alcançar produtividades satisfatória ao produtor, levando em consideração o bom manejo, e respeitar a frequência de corte ideal, em função da área disponível dos cladódios para realização da fotossíntese para a mantença e acúmulo de reservas.

\section{CONSIDERAÇÕES FINAIS}

De maneira geral, a utilização de densidades maiores no cultivo da palma forrageira permite ao pecuarista obter elevada produção de massa verde por hectare e quando associado a estratégia de colheitas bienais, essa produtividade pode ser maximizada devido os cladódios apresentarem maiores áreas durante tal período. Desta forma, o palmal quando implantado e manejado adequadamente em sistemas de sequeiro representa níveis máximos de carboidratos de rápida fermentação e proteína na dieta, possibilitando altos ganhos de peso animal e produtividade por área, mesmo em regiões com baixo índice pluviométrico.

\section{REFERENCIAS}

ANDRADE, D. K. B.; FERREIRA, M. A.; VÉRAS, A. S. C.; WANDERLEY, W. L.; SILVA, L. E.; CARVALHO, F. F. R. Apparent digestibility and absorption of Holstein cows fed diets with forage cactus (Opuntiaficus-indica Mill) in replacement of sorghum silage (Sorghum bicolor (L.) Moench) Revista Brasileira de Zootecnia, v.31, p. 2088-2097, 2002

BAYAR, N.; FRIJI, M.; KAMMOUN, R. Optimization of enzymatic extraction of pectin from Opuntia ficus indica cladodes after mucilage removal. Food Chemistry, v. 241, p. 127-134, 2018.

BEN SALEM, H. A., NEFZAOUI, B. S. L. Supplementing spineless cactus (Opuntia ficus indica f. inermis) based diets with urea treated straw or oldman saltbush (Atriplex nummularia L). Effects on intake, digestion and sheep growth. Journal of Agricultural Science 138, 85-92, 2002.

BISPO, S. V.; FERREIRA, M. A.; VÉRAS, A. S. C.; BATISTA, A. M. V.; PESSOA, R. A. S.; BLEUEL, M. P. Palma forrageira em substituição ao feno de capim-elefante. Efeito sobre consumo, digestibilidade e características de fermentação ruminal em ovinos. Revista Brasileira de Zootecnia, v. 36, n. 6, p. 1902-1909, 2007.

CÂNDIDO FILHO, A.; PEREIRA, F.; LIMA, A. Base alimentar humana com o uso da palma forrageira. VI Simpósio de Reforma Agrária e Questões Rurais. Recife: Instituto Agronômico de Pernambuco, 2014. 
CAVALCANTI, V. A. L. B.; SENA, R.C.; COUTINHO, J. L. B.; ARRUDA, G. P.; RODRIGUES, F. B. Controle das cochonilhas da palma forrageira. Boletim IPA Responde, $n$. 39, p. 1-2, 2001.

CORDOVA TORRES, A. V.; COSTA, R. G.; MEDEIROS, A. N.; ARAÚJO FILHO, J. T.; RAMOS, A. O.; ALVES, N. L. Performance of sheep fed forage cactus with total water restriction. Revista Brasileira de Saúde e Produção Animal, v.18, no.2, p.369-377, 2017.

DUBEUX JÚNIOR, J. C. B., SANTOS, M. V. F. Exigências nutricionais da palma forrageira. In: MENEZES, R. S. C.; SIMÕES, D. A.; SAMPAIO, E. V. S. B. (Org.). A palma no Nordeste do Brasil - conhecimento atual e novas perspectivas de uso. Editora Universitária da UFPE, Recife, p. 105-128, 2010.

DUBEUX JÚNIOR, J. C. B.; SALEM, H. B.; NEFZAOUI, A. Forage Production and supply for animal nutrition. In: Food and agriculture organization of the United Nations. Crop ecology, cultivation and uses of cactus pear. International Center for Agricultural Research in the Dry Areas Rome, p.73-90, 2017.

FARIAS, I.; LIRA, M. A.; SANTOS, D. C. Manejo de colheita e espaçamento da palma forrageira, em consórcio com sorgo granífero, no Agreste de Pernambuco. Pesquisa Agropecuária Brasileira, v. 35, p. 341-347, 2000.

FARIAS, I.; SANTOS, D. C.; DUBEUX JUNIOR, J. C. B. Estabelecimento e manejo de palma forrageira. In: MENEZES, R. S. C.; SIMÕES, D. A.; SAMPAIO, E. V. S. B. (eds). A Palma no Nordeste do Brasil conhecimento atual e novas perspectivas de uso. $2^{\circ}$ ed. Recife: Ed Universitária da UFPE. p.81- 103, 2005.

FERRAZ, A. P. F.; ARRUDA, D. M. P.; MELLO, A. C. L. M. Pragas e doenças. In: LIRA, M. A. (Ed.). Palma forrageira: cultivo e usos. Cadernos do Semiárido: riquezas e oportunidades, 7. CREA-PE, p.39-47, 2017.

FERRAZ, A. P. F.; LIRA, M. A.; SILVA, M. C.; CUNHA, M. V.; SANTOS, M. V. F.; SILVA, P. S. F.; SANTOS, D. C. Cochineal insects in cactus pear genotypes (Opuntia and Nopalea): effect on forage production. Archivos Latinoamericanos de Producción Animal, Grassland and Forage abstracts, v.24, n.5, p.192-193, 2016.

FERREIRA, M. A.; SILVA, F. M.; BISPO, S. V.; AZEVEDO, M. Strategies for the supplementation of dairy cows in the Brazilian semi-arid. Revista Brasileira de Zootecnia, v.38, p.322-329, 2009.

IBGE - Instituto Brasileiro de Geografia e Estatítica. Censo Agropecuário 2017.

INGLESE, P.; LIGUORI, G.; BARRERA, E. Ecophysiology and reproductive biology of cultivated cacti. In: INGLESE, P.; MONDRAGON, C.; NEFZAOUI, A.; SAENZ, C. (Eds.). Crop ecology, cultivation and uses of cactus pear: CAM crops for a hotter and drier world. FAO, International Center for Agricultural Research in the Dry Areas, Rome, p.29-41, 2017.

LARCHER, W. Ecofisiologia Vegetal. São Carlos,SP. RIMA, 530 p., 2000.

LIMA, R. M. B.; FERREIRA, M. A.; BRASIL, L. H. A.; ARAÚJO, P. R. B.; VÉRAS, A. S. C.; SANTOS, D. C.; MAOM, C.; MELO, A. A. S.; OLIVEIRA, T. N.; SOUZA, I. S. Replacement of 
the Corn by Forage Cactus: Ingestive Behavior of Crossbreed Lactating Cows. Acta Scientiarum. Animal Sciences, v. 25, p. 347-353, 2002.

LIRA, M. A.; MELLO, A. C. L.; CUNHA, M. V.; SANTOS, M. V. F.; DUBEUX JÚNIOR, J. C.; LIRA JUNIOR, M. A.; APOLINÁRIO, V. X. O. Produção animal em pastagens tropicais da América Latina. Archivos Latinoamericanos de Producción Animal. v. 25, p. 1-2, 2017.

LIRA, M. A.; SANTOS, M. V. F.; CUNHA, M. V.; MELLO, A. C. L.; FARIAS, I. SANTOS, D. C. Utilização da palma forrageira na pecuária leiteira do semiárido. Anais. Academia

Pernambucana de Ciência Agronômica, v. 2, p.107-120, 2006.

MARQUES, O. F. C; GOMES, L. S. P; MOURTHÉ, M. H. F; BRAZ, T. G. S; NETO, O. S. P. Palma forrageira: cultivo e utilização na alimentação de bovinos. Cad. Ciênc. Agra., v. 9, n. 1, p. 75-93, 2017.

MENEZES, R. S. C., SAMPAIO, E. V. S. B., SALCEDO, I. H., SOUZA, F. J. Produtividade da palma em propriedades rurais. Menezes, R.S.C., Simões, D.A., Sampaio, E.V.S.B., A palma no Nordeste do Brasil - Conhecimento atual e novas perspectivas de uso. Editora Universitária da UFPE, Recife, p. 129 - 142, 2005.

MOURA, A. G. V.; LIRA, M. A.; CAVALCANTI, V. L. B.; SANTOS, M. V. F.; WILLADINO, L. Seleção de clones de palma forrageira resistentes à cochonilha-do carmim (Dactylopius sp).

Revista Brasileira Zootecnia, v.38, p.827-831, 2012.

NEVES, A. L. A.; PEREIRA, L. G. R.; SANTOS, R. D.; VOLTOLINI, T. V.; ARAÚJO, G. G. L.; MORAES, S. A.; ARAGÃO, A. S. L.; COSTA, C. T. F. Plantio e uso da palma forrageira na alimentação de bovinos no semiárido brasileiro. Embrapa Gado de Leite, p. 7, 2010.

NOBEL, P. S.; BARBERA, G.; INGLESE, P.; PIMIENTA-BARRIOS, E. Agroecology, cultivation and uses of cactus pear. FAO, p.36-48, 1995.

OLIVEIRA, F. T.; SOUTO, J. S.; SILVA, R. P.; ANDRADE FILHO, F. C.; PEREIRA JÚNIOR, E. B. Palma forrageira: Adaptação e importância para os ecossistemas áridos e semiáridos.

Revista Verde de Agroecologia e Desenvolvimento Sustentável, v.5, p.27-37, 2010.

RAMOS, J. P. F. Crescimento vegetativo e produtividade da palma forrageira em função do manejo de colheita e da adubação orgânica. Dissertação (Mestrado em Zootecnia). Universidade Federal da Paraíba. 44 p. 2012.

ROCHA, A. G. V.; LIRA, M. A.; CAVALCANTI, V. L. B.; SANTOS, M. V. F.; WILLADINO, L. Seleção de clones de palma forrageira resistentes à cochonilha do carmim (Dactylopius sp.).

Revista Brasileira de Zootecnia, v.38, p.827-831, 2012.

SAMPAIO, E. V. S. B. Fisiologia da palma. In; MENEZES, R.S.C.et al. (eds). A palma no Nordeste do Brasil: conhecimento atual e novas perspectivas de uso. Recife: Editora

Universitária da UFPE, p. 43-55, 2005.

SANTOS, D. C.; FARIAS, I.; LIRA, M. A.; SANTOS, M. V. F.; ARRUDA, G. P.; COELHO, R. S. B.; DIAS, F. M.; WARUMBY, J. F.; MELO, J. N. de. Manejo e utilização da palma forrageira (Oputia e Nopaleia) em Pernambuco: cultivo e utilização. Recife: IPA, 48p. 2006a. 
SANTOS, D. C.; DUBEUX JÚNIOR, J. C. B.; FARIAS, I.; LIRA, M. A.; DIAS, F. M.; PEREIRA, V. L. A. Níveis de nitrogênio e fósforo em palma forrageira (Opuntia ficus-indica) clone IPA-20 sob dois espaçamentos. In: IV Congresso Nordestino de Produção Animal. Petrolina-PE, p. 381-383. 2006b.

SANTOS, D. C.; SILVA, M. C.; DUBEUX JÚNIOR, J. C. B.; LIRA, M. A.; SILVA, R. M. Estratégias para Uso de Cactáceas em Zonas Semiáridas: Novas Cultivares e Uso Sustentável das Espécies Nativas. Revista Científica Produção Animal., v.15, n.2, p.111-121, 2013.

SANTOS, M. V. F.; LIRA, M. A.; DUBEUX JR, J. C. B. Palma forrageira In: Plantas forrageiras. ed. Viçosa: Editora UFV, vol. único, p. 459-493. 2010.

SCHEINVAR, L. Usos e importância das Cactáceas. In: workshop sobre a palma forrageira: usos e perspectivas para o semiárido. Feira de Santana. Anais. Feira de Santana. p. 151., 2012.

SILVA, A. P. G.; SOUZA, C. C. E.; RIBEIRO, J. E. S.; SANTOS, M. C. G.; PONTES, A. L. S.; MADRUGA, M. S. Características físicas, químicas e bromatológicas de palma gigante (Opuntia ficus-indica) e miúda (Nopalea cochenillifera) oriundas do estado da Paraíba. Revista Brasileira de Tecnologia Agroindustrial, v. 9, n. 2, p. 1810-1820, 2015.

SILVA, E. G. B.; MARINHO, A. L.; MOREIRA, J. A.; NOVAES, L. P.; SILVA, A. D. L.; MOTA, L. C. Farelo de palma gigante (opuntia fícus-indica) na alimentação de suínos em crescimento. Acta Veterinaria Brasilica, v.10, n.4, p.314-321, 2016.

SILVA, J. A.; BONOMO, P.; DONATO, S. L. R.; PIRES, A. J. V.; ROSA, A. C. C.; DONATO, P. E. R. Composição mineral em cladódios de palma forrageira sob diferentes espaçamentos e adubações químicas. Revista Brasileira de Ciências Agrárias, Recife, v. 7, supl., p. 866-875, 2012.

SILVA, P. F. Crescimento e produtividade de palma forrageira sob diferentes lâminas de irrigação e adubação nitrogenada. 79 f. Tese (Doutorado em Engenharia Agrícola) -

Universidade Federal de Campina Grande, Campina Grande, 2017.

SOUZA, T. C. Sistemas de cultivo para a palma forrageira cv. Miúda (Nopalea cochenillifera Salm Dyck). Tese (Doutorado em Zootecnia) - Universidade Federal Rural de Pernambuco. 120 p., 2015.

TAIZ, L.; ZEIGER, E.; MOLLER, I. M.; MURPHY, A. Fisiologia e desenvolvimento vegetal. 6. ed. Porto Alegre: Artmed, 858 p, 2017.

VOLPE, M.; GOLDFARB, J. L.; FIORI, L. Hydrothermal carbonization of Opuntia ficus-indica cladodes: Role of process parameters on hydrochar properties. Bioresource Technology, v. 247, p. 310-318, 2018. 